\title{
IOT based Smart Bin Monitoring using Sensor and GSM for Smart Cities
}

\author{
A.Sridhar, N.Madhavi, M.Moqueed Ahmed, G. Mahender
}

\begin{abstract}
Quick increment in population we see modern, mostly dust canister are placed close to open locations within the urban areas/cities are stuffed because of increment within the waste every day. Within the occasion that the switch of waste isn't valid achieved it makes unhygienic circumstance for the humans, to circumvent this kind of condition we are trying to plan "IOT based totally eager canister watching utilizing gsm and sensor for smart urban areas". In this proposed established gadget there are numerous dustbins located in the course of the city, the ones dustbins are supplied with ultrasonic sensor which enables in degree of the trash boxes and a so it is whatever however hard to differentiate which trash receptacle is complete. At the factor whilst the extent arrives at as a long manner as possible, the ultrasonic device will transmit the extent alongside the extent of dustbin those subtleties can be gotten to through the fear specialists from their area with the help of GSM Modem and a set off interest can be made to clean the dustbins
\end{abstract}

\section{INTRODUCTION}

In every day lifestyles, we see the photos of trash receptacles being flood and all the trash spills out bringing approximately contamination. This likewise increments

Quantity of sickness as huge range of inflammation and mosquitoes breed on it. Consequently our difficulty

Explanation is to design a machine based on Arduino for amassing the trash from a particular locale - the

Locale whose open garbage containers are flooding with beyond scenario. Strong waste management is a prime test in urban zones for the sizable majority of the countries at a few degree inside the arena.

A talented waste management for keep a sheltered and green circumstance as there are developing a huge variety of waste switch. There are numerous advancements are carried out for squander collection in reality as for extraordinarily lots oversaw reusing. On this undertaking, we've got supplied a coordinated framework pooled with an integrated association of global Positioning device (GPS) and global machine for cellular communique (GSM).The sensors is probably positioned in the fundamental trash canisters sited on the overall populace locations. At the factor whilst the trash arrives on the diploma of the sensor, at that aspect that sign might be given to Arduino Controller. The controller will gives signal to the driving force of trash collection truck

Revised Manuscript Received on September 14, 2019.

A.Sridhar, Assist. Professor, Department of CSE, Siddhartha Institute of Technology \& Sciences, Narapally, Ghatkesar, Hyderabad, Telangana, India

N.Madhavi, Assist. Professor, Department of CSE, Siddhartha Institute of Technology \& Sciences, Narapally, Ghatkesar, Hyderabad, Telangana, India

M.Moqueed Ahmed, Assist. Prof, Department of ECE, Siddhartha Institute of Technology \& Sciences, Narapally, Ghatkesar, Hyderabad, Telangana, India

G. Mahender, Assist. Professor, Department of CSE, Siddhartha Institute of Technology \& Sciences, Narapally, Ghatkesar, Hyderabad, Telangana, India. approximately which trash field is completely filled and wants crucial attention. Arduino will deliver signal by sending SMS using GSM innovation. At anything point the trash is full facts may be send to the worried position to smooth the canister

\section{Philosophy:}

The power supply is given to the Arduino and the ultrasonic sensor is implemented to understand the degree of trash ,that sensor produce sound wave that wave hit the article and contemplated back to the sensor ,that length of ultrasonic signal is ship to the Arduino controller ,and compute the diploma of trash, simultaneously area likewise find via the use of GPRS to the controller, both information (area, diploma) is send thru the gsm module, that data are put away within the cloud. The net page page is implemented discover the region of smart receptacle and its stage, that web page is applied for residential clients to finding the nearest canister and the truck jumper to discover the courses of the eager container

\section{BLOCK DIAGRAM}

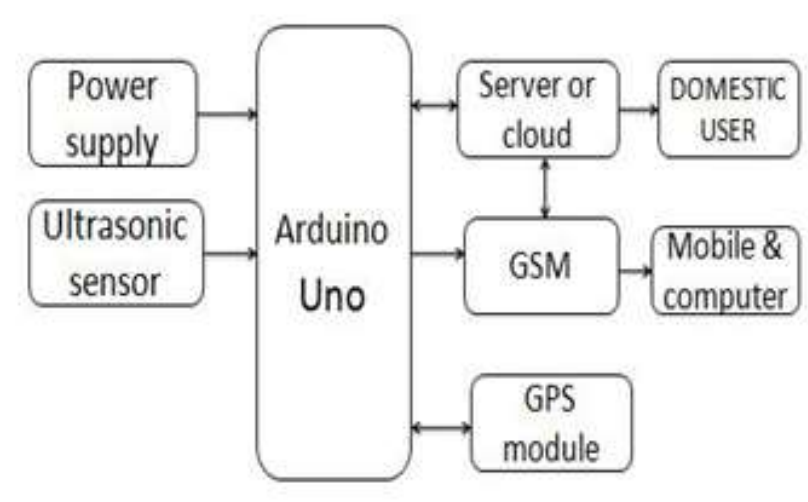

\section{RESULTS AND DISCUSSIONS}

Simple smooth device includes three big segments, as an example, smart Bin, laptop application for metropolitan chamber and site net page

Software for series car drivers and sensible receptacle clients. Basically, the clean easy savvy canister is supposed to peruse and transmit trash diploma subtleties, for instance, tallness diploma of accrued trash. Place of packing containers became likewise be perused and transmitted to the precept server.

The sphere stage readings and associated subtleties were given from sensible canisters were controlled inside
Blue Eyes Intelligence Engineering \& Sciences Publication 
the primary paintings region usage of town board to guarantee valid waste management framework. Those receptacle statuses are moreover verified in excellent container purchaser's net application. On the begin, metropolitan collecting authority registers customers, collection car drivers, and series automobiles, reusing corporations, assortment zones, series guides, savvy boxes and separate Arduino sheets.

Constant searching at approximately assortments is accomplished via Google map API implanted inside the primary art work place software program. Despite the fact that savvy ongoing path guides for collection regions are validated to the collection car cause pressure utilizing smooth smooth flexible application. The number one work region utility interface utilized for checking motive and route course maps showed to the using pressure inside the easy spotless internet application.

\section{APPLICATION}

It very well can be generally utilized in road It applied in colleges, universities

It thoroughly may be utilized in metropolis business organization to make our state of affairs clean

Provide records with admire to closest open receptacles to community customer with the aid folks

\section{CONCLUSION}

The easy easy framework gave an extended manner achieving answers for the human beings the those who are within the city territory with terrific trash locating and collecting. This framework must peruse and transmit present day status of the receptacle to the server. At that thing managed facts required for sturdy waste management the usage of an integrated framework. Growing flexible programs to helped motive force with the collection. At that factor informed household customer previous the gathering through the portable software. Reports identified with the waste collection can be created through this framework. From that factor forward, empowered regular checking of waste series and simple planning moreover performed via this framework. At very last, the assignment effectively performed to satisfy every one of the desires of this framework and expectation this examination could be of advantage. The examination group trusts that this studies could be useful for the analysts who are keen at the factors like waste management, exploring frameworks simply as waste assortment and discoveries. It will likewise deliver higher thoughts and more statistics to execute comparative form of sports activities or hitechnical ventures with further advanced units.

\section{REFERENCES}

1. Kanchan Mahajan, "Squander Bin monitoring machine the use of integrated technologies", global magazine of contemporary research in technology, Engineering and generation, difficulty three ,problem 7 , July 2014

2. M. Al-Maaded, N. K. Madi, RamazanKahraman, A. Hodzic, N. G. Ozerkan , an define of solid Waste control and Plastic Recycling in Qatar, Springer journal of Polymers and the environment, March 2012, extent 20, problem 1, pp 186-194.
3. Islam, M.S. Arebey, M. ; Hannan, M.A. ; Basri, $\mathrm{H}$,"evaluate for robust waste container searching at and collection framework" Innovation control and technology studies (ICIMTR), 2012 global conference , Malacca, $258-262$.

4. Raghumani Singh, C. Dey, M. Strong waste management of Thoubal Municipality, Manipur-a contextual studies green era andEnvironmental Conservation (GTEC 2011), 2011 global convention Chennai $21-24$.

5. Vikrant Bhor, "splendid rubbish the executives machine international magazine of Engineering studies and technology (IJERT),Vol. 4 hassle 03, March-20152000.

6. Md.Abdul Al mamun ,mahammad a.Hannan,Aini hussian, and basri "coordinated detecting framework and calculations for strong waste receptacle country the executives computerization " IEEE trans on sensor diary, January 2015

7. Mahesh N. Jivani, GSM based totally domestic Automation device using App-Inventor for Android cell smartphone. First ed. Worldwide magazine of superior studies in electric powered, Electronics and Instrumentation Engineering, 2014. Internet. 25 July 2016. 